\title{
GORDURA PROTEGIDA SOBRE O DESEMPENHO, CARCAÇA E COMPOSIÇÃO QUÍMICA DA CARNE DE NOVILHOS HOLANDÊS*
}

\author{
PROTECTED FAT AND PERFORMANCE, CARCASS AND MEAT CHEMICAL \\ COMPOSITION IN HOLSTEIN FRISIAN STEERS
}

\author{
Jorge, J.R.V. ${ }^{1}$, L.M. Zeoula ${ }^{1}$, I.N. Prado' ${ }^{1}$, R.R. Silva², R.V. Andrade ${ }^{1}$, L.M.A. Macedo², \\ J.M. Prado ${ }^{1}$, E.E. Bublitz ${ }^{1}$ e J.A. Marques²
}

\begin{abstract}
${ }^{1}$ Universidade Estadual de Maringá. Av. Colombo, 5790. CEP 87020-900. Jd. Universitário. Maringá-Paraná. Brasil. inprado@uem.br

${ }^{2}$ Universidade Estadual do Sudoeste da Bahia. Doutorando em Zootecnia PPZ/UEM. Pça. Primavera, 40. CEP 45700-000. Bairro Primavera. Itapetinga-BA. Brasil. rrsilva.uesb@hotmail.com
\end{abstract}

\section{PalaVRas chaVe adicionaIS}

Caroço de algodão. Colesterol. Ganho de peso. Maciez.

\section{RESUMO}

Objetivou-se com este trabalho avaliar o consumo, desempenho, e características de carcaça e composição da carne de novilhos da raça Holandesa. Foram utilizados 48 novilhos castrados, com idade média de 24 meses e peso médio inicial de $405 \mathrm{~kg}$, distribuídos em um delineamento inteiramente casualizado, num fatorial $2 \times 3$, com (RCG) ou sem (RSG) inclusão de gordura na dieta e três pesos de abate $(450,510$ e $600 \mathrm{~kg})$, com oito repetições. Houve efeito $(p<0,05)$ da inclusão de gordura no consumo de matéria seca, sendo 14,6 $\mathrm{kg} /$ dia para RSG e 13,5 kg/dia para RCG. Os pesos de abate não influenciaram ( $p>0,05)$ os consumos de nutrientes. O ganho médio diário $(1,12 \mathrm{~kg} / \mathrm{dia})$, a conversão alimentar $(12,8 \mathrm{~kg} / \mathrm{kg}$ ganho), o rendimento de carcaça $(47,8 \%)$, a espessura de gordura $(4,82 \mathrm{~mm})$, área de olho de lombo $(109,5$ $\mathrm{cm}^{2}$ ) e área de olho de lombo/100 kg de carcaça $\left(43,3 \mathrm{~cm}^{2} / 100 \mathrm{~kg}\right)$ não foram afetadas pela inclusão de gordura ou pelos pesos de abate. A quebra no resfriamento foi maior para o abate com $450 \mathrm{~kg}$ do que para os demais (510 e $600 \mathrm{~kg}$ ). Não houve efeito $(p<0,05)$ da inclusão de gordura nos teores proteína $(22,76 \%)$, umidade $(73,95 \%)$, matéria graxa $(2,50 \%)$ e colesterol $(57,58 \mathrm{mg} / 100 \mathrm{~g}$ músculo).

*Parte da Tese de Doutorado do Primeiro Autor $\mathrm{PPZ} / \mathrm{DZO} / \mathrm{UEM}$.

Recibido: 4-9-07. Aceptado: 1-4-08.

\section{AdDitional KEYWORDS}

Cholesterol. Cottonseed. Tenderness. Weight gain.

\section{SUMMARY}

The objective of the present work was to evaluate intake, performance, carcass characteristics and chemical meat composition of Holstein steers. Forty eight castrated steers, with an average age of 24 months and an initial average weight of $405 \mathrm{~kg}$, were used; they were distributed into a completely randomized set, with (WFR) or without (WTFR) fat inclusion in the diet and three slaughter weights $(450,510$ and $600 \mathrm{~kg})$, with eight repetitions. The inclusion of fat in the diet caused an effect $(p<0.05)$ on the intake of dry matter, being $14.6 \mathrm{~kg} /$ day for WTFR and $13.5 \mathrm{~kg} /$ day for WFR. The slaughter weights did not influence $(p>0.05)$ the intake of nutrients. The daily average gain ( $1.12 \mathrm{~kg} / \mathrm{day})$, the feed conversation ratio $(12.8 \mathrm{~kg} / \mathrm{kg}$ gain), dressing percentage $(47.8 \%)$, back fat thickness $(4.82 \mathrm{~mm})$, rib eye area $\left(109.5 \mathrm{~cm}^{2}\right)$ and rib eye area/100 kg of muscle $\left(43.3 \mathrm{~cm}^{2} / 100 \mathrm{~kg}\right)$ were not affected by the fat inclusion or by the slaughter weights. Chilling loss was higher at slaughter at $450 \mathrm{~kg}$ as compared with the others $(510$ and $600 \mathrm{~kg})$. There was no effect $(p<0.05)$ of the fat inclusion on the contents of protein $(22.76 \%)$, moisture $(73.95 \%)$, fat $(2.50 \%)$, and cholesterol ( $57.58 \mathrm{mg} / 100 \mathrm{~g}$ muscle).

\section{INTRODUÇÃO}

Uma alternativa que poderia contribuir para aumentar a oferta de carne e melhorar

Arch. Zootec. 58 (223): 371-382. 2009. 
a rentabilidade do produtor de leite no Brasil, que explora raças puras ou cruzamentos com alto grau de sangue leiteiro, seria a criação de bezerros. Entretanto, tal prática tem sido considerada inviável economicamente, o que tem levado ao abate destes animais ao nascer ou à venda para fins industriais (Campos et al., 1996).

Em vários trabalhos, como Rodrigues Filho et al. (2003) e têm-se verificado que os bezerros provenientes de rebanhos leiteiros apresentam potencial para ganho de peso, em virtude de sua precocidade e eficiência alimentar, com elevado rendimento e qualidade de carcaça. Entretanto, constatase que a alimentação consiste no principal fator no custo de produção, sobretudo na fase de aleitamento ( $80-90 \%)$, o que indica a necessidade de práticas de manejo alimentar que busquem o aumento da eficiência como a utilização de alimentos de menor custo e uso de volumoso de boa qualidade (Ribeiro, 1997).

Com o aumento do tempo de alimentação em confinamento, há tendência de redução da eficiência de transformação de alimentos em ganho de peso, em função de alterações na composição do ganho de peso, pois há maior deposição de gordura e aumento do gasto com manutenção, à medida que o peso de abate se aproxima do peso maduro da raça (Di Marco, 1994).

Como a eficiência de transformar alimentos consumidos em ganho de peso decresce com o aumento da idade do animal, buscar a redução da idade de abate é fundamental para tornar o sistema de produção mais eficiente (Costa et al., 2002).

A exigência de acabamento nas carcaças comercializadas para os frigoríficos é bem conhecida pelos pecuaristas, pois os animais que não atingem o grau de cobertura mínimo exigido são punidos, sofrendo deságio no preço final por arroba comercializada (Abrahão, 2004), sendo estas carcaças classificadas como pele fina. Segundo Costa (2002), o grau mínimo de cobertura exigido varia entre 3,0 e $6,0 \mathrm{~mm}$ de espessura de gordura subcutânea.

Animais oriundos de plantéis de raças leiteiras são depreciados no mercado de reposição (boi magro), pois na maioria das vezes são abatidos sem a devida suplementação na fase de terminação, acarretando em descontos no valor recebido, quando do abate destes animais, devido ao baixo grau de acabamento das carcaças.

Para tentar minimizar este problema é preciso abater estes animais em diferentes pesos para avaliar as características da carcaça e também utilizar estratégias nutricionais para melhoria destas carcaças, com a utilização de concentrado na terminação, contendo gordura protegida na dieta destes animais. Dessa forma, objetivou-se com este trabalho avaliar o consumo, desempenho, características de carcaça de novilhos, provenientes de rebanhos leiteiros, alimentados com dietas com ou sem gordura protegida em três pesos de abate $(450,510$ e $600 \mathrm{~kg})$.

\section{MATERIAL E MÉTODOS}

O experimento foi desenvolvido no Setor de Bovinocultura de Corte da Fazenda Experimental de Iguatemi, no Laboratório de Análises de Alimentos e Nutrição Animal, no Laboratório de Química pertencentes à Universidade Estadual de Maringá e num abatedouro comercial da região, Frigorífico Fripanema.

Foram utilizados 48 novilhos castrados, com grau de sangue variando de $15 / 16$ a PO, da raça Holandesa $\mathrm{P} \& \mathrm{~B}$, com idade aproximada de 24 meses e $405 \mathrm{~kg}$ de peso vivo. Os animais foram pesados, vermifugados com o produto Dectomaxâ, à base de doramectina, na proporção de $1,0 \mathrm{ml}$ de produto para cada $50 \mathrm{~kg}$ de peso vivo, vacinados contra febre aftosa e identificados com brincos plásticos.

Os animais distribuídos, com peso médio inicial de 405,0 kg para os tratamentos com e sem gordura protegida, sendo 24 animais por tratamento. Ao determinar-se os pesos 


\section{DESEMPENHO EM CONFINAMENTO COM OU SEM GORDURA PROTEGIDA}

de abate $(450,510$ e $600 \mathrm{~kg})$, então, os animais foram divididos em três grupos definidos em função do peso de abate, com pesos iniciais de 350,$9 ; 388,2$ e $477,3 \mathrm{~kg}$, respectivamente, para os pesos de abate de $450 ; 510$ e $600 \mathrm{~kg}$. Assim, ficando 16 animais para cada peso de abate, sendo oito para cada tratamento (com e sem gordura protegida).

Os animais foram alojados em baias de $10 \mathrm{~m}^{2}$, sendo estas cercadas com vergalhões de ferro, com piso de concreto, parcialmente coberto com telhas de zinco, estando o cocho de alimentação na parte coberta, com $2 \mathrm{~m}$ lineares/baias, e o bebedouro, com capacidade para 250 litros, na parte descoberta. Foram realizadas limpezas diárias nas baias durante todo o período experimental.

As dietas foram formuladas para atender as exigências estabelecidas pelo NRC (1996) para ganho de peso de 1,2 kg/animal/dia. O fornecimento de matéria seca (MS) das dietas foi estipulado de forma a permitir até $10 \%$ de sobras. Os alimentos utilizados foram: silagem de milho, farelo de algodão, casca de algodão, caroço de algodão, milho, suplemento mineral e calcário. A composição destes alimentos está descrita na tabela $\mathbf{I}$. As dietas foram formuladas para serem isoprotéicas e isoenergéticas, de forma que a primeira tivesse somente o milho como fonte principal de energia (RSG), e a segunda com a inclusão do caroço de algodão como fonte alternativa de energia e gordura protegida para os animais (RCG).

As dietas foram enriquecidas com calcário e suplemento mineral Phospec $90 \AA$, tendo a seguinte composição para cada $\mathrm{kg}$ de produto, Ca: $140 \mathrm{~g}, \mathrm{P}: 90 \mathrm{~g}, \mathrm{Na}: 115 \mathrm{~g}, \mathrm{Mg}$ : 12 g, S : 15 g, F: 0,9 g, Cu: 1650 mg, Zn: 4060 mg, Mn: 1480 mg, Fe: 1901 mg, I: 90 mg, Co: $90 \mathrm{mg}$ e Se: $26,5 \mathrm{mg}$. As dietas foram fornecidas duas vezes ao dia, pela manhã $(08: 00 \mathrm{~h})$ e pela tarde $(16: 30 \mathrm{~h})$. Todos os dias, antes do fornecimento pela manhã, as sobras foram recolhidas, pesadas, para o controle do consumo e da quantidade fornecida, sendo estas identificadas e congeladas para posteriores análises. $\mathrm{O}$ ajuste do consumo foi feito a cada quatro dias. Foi fornecida água à vontade durante o experimento. Os cochos de água foram limpos semanalmente.

As composições percentuais e químicas das dietas são apresentadas na tabela II. A relação volumoso: concentrado foi de 45:55, sendo que como fonte de volumoso foi utilizado silagem de milho e a casca de algodão.

Os animais foram pesados e distribuídos nos tratamentos, iniciando um período de sete dias de adaptação, após o qual, iniciou-

Tabela I. Composição química dos alimentos. (Chemical composition of the diet ingredients).

\begin{tabular}{lcccccccc}
\hline Alimentos & MS (\%) & PB $^{*}$ & FDN* & FDA* & EE $^{*}$ & AM $^{*}$ & ELm & ELg \\
\hline Milho & 88,0 & 9,4 & 12,0 & 4,5 & 3,9 & 76,7 & 2013 & 1357 \\
Farelo de algodão & 94,2 & 46,1 & 28,0 & 16,0 & 1,6 & 3,7 & 1861 & 1227 \\
Caroço de algodão & 94,4 & 23,5 & 51,5 & 39,3 & 19,0 & 1,5 & 2029 & 1371 \\
Casca de algodão & 92,2 & 10,9 & 83,7 & 62,3 & 3,3 & 1,6 & 1239 & 671 \\
Silagem de milho & 35,6 & 7,68 & 62,4 & 35,9 & 2,5 & 14,2 & 1393 & 812 \\
Suplemento mineral & 99,0 & - & - & - & - & - & - & - \\
Calcário & 99,0 & - & - & - & - & - & - & -
\end{tabular}

MS: matéria seca; PB: proteína bruta; FDN: fibra em detergente neutro; FDA: fibra em detergente ácido; EE: extrato etéreo; $\mathrm{AM}$ : amido. ${ }^{*} \%$ de matéria seca.

ELm: energia líquida de mantença (kcal/kg); ELg: energia líquida de ganho (kcal/kg), segundo Kearl (1982). 
Tabela II. Composição percentual e química das dietas experimentais sem (RSG) ou com gordura (RCG). (Percentage and chemical composition of the experimental diets without (RSG) or with fat (RCG)).

\begin{tabular}{lcc}
\hline Variáveis & RSG & RCG \\
\hline Milho & 45,31 & 36,44 \\
Farelo de algodão & 9,04 & 2,85 \\
Caroço de algodão & - & 15,06 \\
Suplemento mineral & 0,32 & 0,32 \\
Calcário & 0,32 & 0,32 \\
Casca de algodão & 27,00 & 27,00 \\
Silagem de milho & 18,00 & 18,00 \\
Total & 100 & 100 \\
& & \\
Matéria seca (\%) & 80,3 & 80,9 \\
Proteína bruta* & 12,8 & 12,6 \\
Fibra em detergente neutra* & 41,8 & 46,8 \\
Fibra em detergente ácida* & 26,8 & 31,3 \\
Extrato etéreo* & 3,3 & 5,7 \\
Amido* & 38,1 & 31,3 \\
Nutrientes digestíveis totais* & 71,2 & 71,6 \\
Energia líquida (kcal/kg) & & \\
$\quad$ - de mantença & 1666 & 1678 \\
$\quad$ - para ganho & 1053 & 1063 \\
Cálcio* & 0,31 & 0,32 \\
Fósforo* & 0,30 & 0,32 \\
\hline
\end{tabular}

*\% de matéria seca.

se o experimento. As pesagens subseqüentes foram a cada 28 dias de confinamento até o abate. A pesagem sempre ocorreu pela manhã, em jejum de alimentos sólidos, ou seja, depois da alimentação da tarde e antes da alimentação da manhã, sendo recolhidas as sobras às 17:00 h do dia anterior à pesagem.

Análises químicas do concentrado fornecido, das sobras e da silagem foram feitas análises para determinação de matéria seca(MS), matéria orgânica (MO), extrativo não nitrogenado (ENN), proteína bruta $(\mathrm{PB})$, energia bruta (EB), fibra em detergente neutro (FDN), fibra em detergente ácido (FDA) e fibra bruta (FB), segundo métodos da AOAC (1984), descritos conforme Silva (1990). Para determinação do amido foi uti- lizado o método enzimático descrito por Poore et al. (1989), adaptado por Pereira e Rossi (1995).

A determinação dos teores de nutrientes digestíveis totais (NDT) para o milho, farelo de algodão, casca de algodão, caroço de algodão e silagem de milho foi baseada na composição química dos alimentos, utilizando as equações descritas por Kearl (1982).

Os valores de energia metabolizável (EM), energia liquida de mantença (ELm) e energia líquida de ganho (ELg) foram calculadas conforme recomendações de Sniffen et al. (1992).

Antes do abate, os animais foram pesados depois de um período de jejum de 14 horas. Os abates foram realizados em abatedouro comercial (Frigorífico Fripanema, em Colorado, PR), seguindo o fluxo normal do estabelecimento. As carcaças foram submetidas à avaliação, onde foram estudados rendimento, peso de carcaça quente, peso da carcaça fria, área de olho de lombo, área de olho de lombo por $100 \mathrm{~kg}$ de carcaça, espessura de gordura externa e quebra no congelamento. Na meia-carcaça esquerda, entre a $12^{\mathrm{a}}$ e a $13^{\mathrm{a}}$ costelas, foi feito um corte para expor a seção transversal do músculo Longissimus. A área de olho de lombo foi determinada a partir dessa seção, desenhada diretamente por sobreposição em papel vegetal, sendo posteriormente digitalizada com auxílio de mesa digitalizadora e calculada a área por meio do software Springâ versão 3.6.03 (INPE, 2002). A espessura de gordura subcutânea também foi determinada nessa mesma peça, com o uso de um paquímetro digital, sendo feita à média de três medições.

As amostras do músculo Longissimus foram então congeladas e armazenadas para as análises químicas posteriores. O descongelamento das amostras foi feito em temperatura ambiente, sendo retirada toda a gordura de cobertura, restando apenas o músculo Longissimus, e analisadas em triplicata.

Foram determinados os teores de 


\section{DESEMPENHO EM CONFINAMENTO COM OU SEM GORDURA PROTEGIDA}

umidade, proteína, matéria graxa total e cinzas, conforme AOAC (1984).

A quantificação do colesterol foi determinada através de um cromatógrafo gasoso Shimadzu 14A equipado com detector de ionização de chama e coluna capilar de sílica fundida ( $25 \mathrm{~m}$ de comprimento, $0,25 \mathrm{~mm}$ de diâmetro interno e $0,20 \mathrm{~mm}$ de SE-30). A identificação do colesterol efetuada por comparação com padrões da Sigma (EUA), conforme Al-Hasani et al. (1993).

O delineamento experimental foi inteiramente casualizado, num fatorial $2 \times 3$, com ou sem inclusão de gordura e três pesos de abate, com oito repetições/tratamento. O peso vivo inicial foi utilizado como covariável. As análises estatísticas das variáveis estudadas foram interpretadas por análises de variância e regressão e as diferenças avaliadas pelo teste Tukey a 5\%, utilizando o Sistema de Análises Estatísticas e Genéticas (SAEG).

\section{RESULTADOSEDISCUSSÃO}

Os resultados apresentados na tabela III mostram que não houve interação $(p>0,05)$ entre a inclusão ou não de gordura na dieta e os pesos de abate para as variáveis de consumo, desempenho e características de carcaça.

Nenhuma das variáveis para consumo de nutrientes sofreu influência $(p>0,05)$ em relação ao aumento do peso de abate, estando de acordo com diversos autores (Moody et al., 1970; Van Koevering et al., 1995; Restle et al., 1997; Costa et al., 2002).

Os CMS, expressos em $\mathrm{kg} / \mathrm{dia}$ e \% PV, foram influenciados negativamente $(p<0,05)$ pela utilização do caroço de algodão na dieta.

CPB foi afetado pela inclusão de gordu$\mathrm{ra}(\mathrm{p}<0,05)$, com valores de $1,86 \mathrm{~kg} /$ dia para o RSG e $1,70 \mathrm{~kg} /$ dia para RCG. O menor consumo de PB para RCG foi ocasionado pelo menor CMS, visto que as rações eram isoprotéicas.

O CFDN não foi afetado $(p>0,05)$ pela utilização de gordura nas dietas, sendo os valores médios de $6,21 \mathrm{~kg} /$ dia, 1,39\% PV. Isso pode ter ocorrido, pois apesar do CMS de RSG ter sido maior, esta ração apresentava 12,0\% menos FDN em sua formulação.

Da mesma forma, o CFDA não sofreu influência $(p>0,05)$ dos tratamentos, com valores de 4,21 kg/dia, 43,3 g/ $\mathrm{kg}^{0,75}$ e $0,94 \%$ PV. Também pode ter ocorrido pela diferença de teores entre as rações $(14,4 \%)$.

A inclusão de gordura na dieta afetou negativamente $(p<0,05)$ o CEE. Essa diferença no CEE pode ser explicada pela formulação das dietas, sendo que RCG continha $73 \%$ mais de EE na sua composição do que RSG.

O CAmido diferiu $(p<0,05)$ entre os tratamentos. O CAmido superior para RSG pode ser explicado pelo maior CMS deste tratamento aliado ao maior teor de amido na

Tabela III. Consumo de matéria seca, proteína bruta, fibra em detergente neutro, fibra em detergente ácido, extrato etéreo, amido e coeficientes de variação $(\mathrm{CV})$ de animais alimentados com rações sem (RSG) e com gordura (RCG). (Dry matter, crude protein, neutral detergent fiber, acid detergent fiber, ether extract, starch intake, and variation coefficients (CV) of animals fed without (RSG) and with fat (RCG).

\begin{tabular}{|c|c|c|c|c|}
\hline \multicolumn{2}{|c|}{ Consumo } & \multirow{2}{*}{$\begin{array}{c}\text { RSG } \\
14,6^{a}\end{array}$} & \multirow{2}{*}{$\begin{array}{c}\text { RCG } \\
13,5^{b}\end{array}$} & \multirow{2}{*}{$\frac{\mathrm{CV}(\%)}{7,6}$} \\
\hline MS & $\mathrm{kg} / \mathrm{dia}$ & & & \\
\hline & $\mathrm{g} / \mathrm{kg}^{0,75}$ & 150,0 & 138,3 & 7,0 \\
\hline \multirow[t]{2}{*}{ PB } & $\mathrm{kg} / \mathrm{dia}$ & $1,86^{\mathrm{a}}$ & $1,70^{\mathrm{b}}$ & 7,4 \\
\hline & $\mathrm{g} / \mathrm{kg}^{0,75}$ & 19,1 & 17,4 & 6,8 \\
\hline \multirow[t]{2}{*}{ FDN } & kg/dia & 6,14 & 6,29 & 7,8 \\
\hline & $\mathrm{g} / \mathrm{kg}^{0,75}$ & 62,9 & 64,5 & 7,3 \\
\hline \multirow[t]{2}{*}{ FDA } & $\mathrm{kg} / \mathrm{dia}$ & 3,94 & 4,21 & 7,6 \\
\hline & $\mathrm{g} / \mathrm{kg}^{0,75}$ & 40,3 & 43,3 & 7,1 \\
\hline \multirow[t]{2}{*}{ EE } & $\mathrm{kg} / \mathrm{dia}$ & $0,48^{b}$ & $0,76^{a}$ & 7,6 \\
\hline & $\mathrm{g} / \mathrm{kg}^{0,75}$ & $4,9^{b}$ & $7,8^{\mathrm{a}}$ & 7,2 \\
\hline \multirow{2}{*}{\multicolumn{2}{|c|}{ amido $\mathrm{kg} / \mathrm{dia}$}} & $5,52^{a}$ & $4,20^{\mathrm{b}}$ & 7,5 \\
\hline & & 56,6 & 43,1 & 6,8 \\
\hline
\end{tabular}

Médias seguidas de letras na mesma linha diferem $(p<0,05)$ pelo teste Tukey. 
formulação desta dieta, possuindo $22 \%$ a mais de amido que RCG.

A diminuição no CMS com a adição de gordura na dieta não foi constatada por Zinn et al. (2000), estes autores concluíram que o uso de $6 \%$ de gordura não alterou o CMS, com os seguintes valores 8,$77 ; 8,41$; 8,46 e $8,62 \mathrm{~kg} /$ dia, respectivamente para os quatro tratamentos. Hill e West (1991) usaram $4,5 \%$ de gordura protegida em confinamento de novilhas e não verificaram diferenças no CMS $(9,9 \mathrm{~kg})$ em relação às dietas que não levaram este produto.

O CMS encontrado neste experimento foi alto, em relação àqueles mostrados na literatura para bovinos leiteiros. Leme et al. (2000), observaram CMS de 10,97 kg/dia, para animais inteiros da raça Holandesa com $459 \mathrm{~kg}$ de peso de abate. Hussein e Berger (1995), obtiveram valores de CMS variando entre 7,96 e $8,59 \mathrm{~kg} / \mathrm{dia}$. Comerford et al. (2001), determinaram valores de CMS de no máximo $11 \mathrm{~kg} /$ dia, para animais em pastejo de alfafa.

O elevado CMS encontrado neste trabalho, independente dos tratamentos, pode estar relacionado ao uso da casca de algodão. De acordo com Hall e Akinyode (2000), os dados encontrados na literatura sugerem que o uso de casca de algodão na dieta tem proporcionado consumos superiores sem, no entanto, aumentar a produtividade animal, indicando que a casca de algodão não tem o mesmo efeito de redução no consumo como outros volumosos. Embora, geralmente o teor de FDN esteja correlacionado negativamente com o CMS, isto não tem acontecido com a casca de algodão. Além disso, os animais da raça Holandesa possuem maior capacidade de ingestão de alimentos e atividade metabólica, pois ao serem submetidos à seleção leiteira, esta tende a privilegiar animais com maior desenvolvimento de órgãos e vísceras (Sartori e Mollo, 2007).

Magalhães et al. (2003), avaliando o consumo de bovinos mestiços de origem leiteira com predominância de sangue Holandês, alimentados com $30 \%$ de casca de algodão em substituição à silagem de capim elefante, observaram CMS de 3,38\% PV e CFDN de 1,63\% PV, valores estes superiores aos do presente trabalho.

Nas tabela IV, constam as médias de peso vivo inicial (PI), ganho médio diário (GMD), conversão alimentar (CAMS) e peso de abate.

A utilização de gordura protegida na dieta de novilhos leiteiros e os diferentes pesos de abate não afetaram $(p>0,05)$ o

Tabela IV. Valores de peso vivo inicial, peso de abate, ganho médio diário (GMD), conversão alimentar da matéria seca (CAMS), dias de confinamento, características de carcaça e coeficientes de variação (CV) de animais alimentados com dietas sem (RSG) ou com gordura (RCG) e abatidos aos 450, 510 e $600 \mathrm{~kg}$. (Values of initial live weight, slaughter weight, average daily gain (GMD), feed:gain ratio, feedlot days, carcass traits, and variation coefficient (CV) of animals fed without (RSG) or with fat (RCG) and slaughtered at 450, 510, and $600 \mathrm{~kg}$ ).

\begin{tabular}{lcccccc}
\hline & \multicolumn{2}{c}{ Tratamentos } & \multicolumn{3}{c}{ Peso de abate (kg) } \\
& RSG & RCG & 450 & 510 & 600 & CV (\%) \\
& & & & & & \\
\hline Peso vivo inicial (kg) & 405,6 & 405,6 & $350,9^{\mathrm{c}}$ & $388,2^{\mathrm{b}}$ & $477,3^{\mathrm{a}}$ & 11,1 \\
Peso abate (kg) & 521,4 & 523,2 & $455,9^{\mathrm{c}}$ & $509,3^{\mathrm{b}}$ & $601,8^{\mathrm{a}}$ & 5,4 \\
Ganho de peso vivo (kg/dia) & 1,123 & 1,120 & 1,069 & 1,062 & 1,238 & 18,6 \\
Ganho de peso vivo relativo (kg/UA) & 1,133 & 1,134 & $1,226^{\mathrm{a}}$ & $1,111^{\mathrm{ab}}$ & $1,063^{\mathrm{b}}$ & 20,1 \\
Conversão alimentar (kg MS/kg ganho) & 13,5 & 12,3 & 12,5 & 13,7 & 12,5 & 20,2 \\
\hline
\end{tabular}

Médias seguidas de letras na mesma linha diferem $(p<0,05)$ pelo teste Tukey.

Archivos de zootecnia vol. 58, núm. 223, p. 376. 


\section{DESEMPENHO EM CONFINAMENTO COM OU SEM GORDURA PROTEGIDA}

ganho de peso dos animais $(1,12 \mathrm{~kg} / \mathrm{dia})$.

Prado et al. (1995) avaliaram o desempenho de novilhos Nelore confinados com dois níveis de caroço de algodão ( 15 ou $30 \%$ da MS), associados à cana-de-açúcar ou capim elefante, e não constataram diferença entre os tratamentos para GMD $(0,96 \mathrm{~kg}$ para $15 \%$ e $0,89 \mathrm{~kg}$ para $30 \%$ ).

O GMD do presente experimento $(1,12$ $\mathrm{kg} / \mathrm{dia}$ ) foi superior ao obtido por Leme et al. (2000), que observaram $0,83 \mathrm{~kg} /$ dia para machos inteiros da raça Holandesa. Também foi superior aos encontrados por Rodrigues Filho et al. (2003), que avaliaram o desempenho de novilhos de origem leiteira com grau de sangue obtiveram ganhos variando de 0,83 a $1,18 \mathrm{~kg} / \mathrm{dia}$.

Comeford et al. (2001), avaliando sistemas de produção para novilhos holandeses, encontraram valores de GMD de 1,35 $\mathrm{kg}$ /dia para animais em pastejo de alfafa seguido de confinamento com dietas ricas em grãos, de $1,31 \mathrm{~kg} /$ dia para tratamento semelhante ao anterior.

A conversão alimentar não apresentou diferença $(p>0,05)$ entre os tratamentos. Entretanto, vários trabalhos com diferentes fontes de gordura demonstraram que a CAMS é melhorada quando a dieta contém níveis mais altos de gordura (Ngidi et al., 1990; Sutter et al., 2000; Zinn et al., 2000).

A elevada CAMS encontrada neste trabalho $(12,82 \mathrm{~kg} / \mathrm{kg}$ ganho) pode ser explicada pelo alto CMS registrado para os animais em estudo, possivelmente causado pela utilização da casca de algodão ( $27 \%$ na dieta).

Não houve efeito $(p>0,05)$ da inclusão de gordura nem do peso de abate no RC Levy et al. (1975), estudando bovinos machos não castrados da raça Holandesa não encontraram diferenças no RC com o aumento do peso de abate de 400 para $500 \mathrm{~kg}$.

Leme et al. (2000), avaliando animais de diferentes cruzamentos, inclusive Holandês, terminados em confinamento e abatidos com 448, 493 e $515 \mathrm{~kg}$ não reportaram diferenças no RC. Por outro lado, outros autores encontraram diferenças no $\mathrm{RC}$ com o aumento do peso de abate. Aumento linear no rendimento de carcaça quente entre 550 e $700 \mathrm{~kg}$ de peso vivo com machos cruzados, não-castrados, de raças continentais de gado de corte foram encontrados por Patterson et al. (1994) e Galvão et al. (1991).

Os dados do presente trabalho estão de acordo com o relatado por Prado et al. (1995), quando usaram alimentação com caroço de algodão e não observaram influência sobre o RC. Segundo Moletta (1999), animais mestiços Canchim não apresentaram diferença no RC quando foram alimentados com soja grão $(54,69 \%)$ ou caroço de algodão $(56,12 \%)$ ambos fornecidos como $20 \%$ do concentrado.

Resultados experimentais, de modo geral, têm mostrado maiores RC para os grupos genéticos originários de raças de corte, quando comparados àqueles originários de raças leiteiras ou seus mestiços (Galvão et al., 1991; Peron et al., 1993; Leme et al., 2000; Fernandes et al., 2004). Além disso, o RC $(47,5 \%)$ foi baixo em relação aos dados de literatura para animais da raça Holandesa e seus mestiços (Apple et al., 1991; Comerford et al., 1992; Hussein e Berger, 1995; Taxler et al., 1995; Comerford et al., 2001; Alves et al., 2004). Em relação aos observados por Leme et al. (2000), os resultados foram mais próximos.

A quebra de peso da carcaça durante o resfriamento decresceu $(p<0,05)$ com o aumento do peso de abate, embora somente o abate com $450 \mathrm{~kg}$ mostrou-se diferente dos de 510 e $600 \mathrm{~kg}$, em decorrência da menor perda de líquidos durante o resfriamento, porque a gordura que recobre a carcaça atua como isolante, reduzindo as perdas por desidratação (Muller, 1987).

Foi observado que no abate aos $450 \mathrm{~kg}$ a quebra durante o resfriamento foi 47 e $59 \%$ superior do que no abate aos 510 e $600 \mathrm{~kg}$, respectivamente. Segundo Restle et al. (1997), a variação na quebra no resfriamento está associada às oscilações que ocorrem na câmara fria (temperatura, velocidade do 
vento, número de carcaças). No presente estudo, embora todos os animais tenham sido abatidos no mesmo frigorífico e resfriados na mesma câmara fria, os abates ocorreram em datas diferentes, havendo possibilidade de terem ocorrido oscilações no ambiente da câmara fria. Em seu estudo, Galvão et al. (1991) verificaram que em animais abatidos com peso equivalente a 90,100 e $110 \%$ do peso adulto, a quebra no resfriamento também decresceu, sendo de 2,55; 1,90 e 1,84\%, respectivamente. Quebras semelhantes foram relatadas por Brondani et al. (2004) para bovinos Aberdeen Angus e Hereford alimentados com diferentes níveis de energia.

Não houve efeito da inclusão de gordura na dieta nem do peso de abate $(\mathrm{p}>0,05)$ sobre a espessura de gordura. A espessura da gordura de cobertura da carcaça é muitas vezes prejudicada num sistema de abate comercial, devido à retirada de parte da mesma junto com o couro. O coeficiente de variação alto $(30 \%)$ entre os tratamentos pode ter mascarado a tendência de aumento na gordura de cobertura verificada para os pesos de abate de 450,510 e $600 \mathrm{~kg}$, com valores de 4,25, 4,88 e 5,68 $\mathrm{mm}$, respectivamente. Esses valores estão acima do mínimo exigido pelos frigoríficos ( $3 \mathrm{~mm})$, indicando que bovinos provenientes de rebanhos leiteiros podem produzir carcaças aceitáveis para o mercado.

As medidas da área de olho de lombo (tabela V) não apresentaram valores diferentes $(p>0,05)$ entre os tratamentos, quando medidas diretamente na carcaça ou em relação a $100 \mathrm{~kg}$ de carcaça. Isto também foi constatado por Ngidi et al. (1990) que observaram que o uso de gordura protegida, a $0,2,4$ ou $6 \%$ da MS, para engorda de novilhos, não influenciou a espessura de gordura da carcaça $(1,5 ; 1,4 ; 1,7$ e $1,4 \mathrm{~cm})$ e $\mathrm{a}$ área de olho de lombo $(76,6 ; 75,2 ; 79,0 \mathrm{e}$ $\left.75,6 \mathrm{~cm}^{2}\right)$, mesmo quando o peso da carcaça diminuiu. O mesmo resultado também foi observado por Zinn et al. (2000), no trabalho com gordura e sebo, onde concluíram que estas dietas não tiveram efeito sobre a área de olho de lombo $\left(88,8 ; 91,2 ; 91,1\right.$ e 94,3 $\left.\mathrm{cm}^{2}\right)$ ou sobre a gordura subcutânea $(0,81 ; 0,84$; $0,89$ e $0,91 \mathrm{~cm})$.

Apple et al. (1991) reportaram valores de $66,44 \mathrm{~cm}^{2}$ para AOL e $6,4 \mathrm{~mm}$ para espessura de gordura ao testarem o desempenho de novilhos holandeses. Peron et al. (2003), estudando novilhos mestiços Nelore $\mathrm{x}$ Holandês e Gir x Holandês quanto à

Tabela $\boldsymbol{V}$. Valores de dias de confinamento e características de carcaça e coeficientes de variação $(C V)$ de animais alimentados com dietas sem (RSG) ou com gordura (RCG) e abatidos aos 450, 510 e $600 \mathrm{~kg}$. (Values of feedlot days and carcass traits and variation coefficient $(\mathrm{CV})$ of animals fed without (RSG) or with fat (RCG) and slaughtered at 450, 510, and $600 \mathrm{~kg}$ ).

\begin{tabular}{|c|c|c|c|c|c|c|}
\hline & \multicolumn{2}{|c|}{ Tratamentos } & \multicolumn{3}{|c|}{ Peso de abate $(\mathrm{kg})$} & \multirow[b]{2}{*}{ CV $(\%)$} \\
\hline & RSG & RCG & 450 & 510 & 600 & \\
\hline Período de confinamento (dia) & 108 & 108 & 100 & 121 & 104 & 37,8 \\
\hline Peso de carcaça quente (kg) & 248,6 & 248,4 & $214,1^{c}$ & $241,1^{\mathrm{b}}$ & $290,3^{a}$ & 7,1 \\
\hline Rendimento de carcaça (\%) & 47,6 & 47,4 & 47,0 & 47,3 & 48,2 & 3,2 \\
\hline Peso de carcaça fria $(\mathrm{kg})$ & 244,1 & 243,8 & $208,9^{c}$ & $237,1^{\mathrm{b}}$ & $285,8^{a}$ & 7,2 \\
\hline Quebra no resfriamento (\%) & 1,88 & 1,91 & $2,46^{a}$ & $1,67^{b}$ & $1,55^{\mathrm{b}}$ & 22,3 \\
\hline Espessura de gordura externa (mm) & 4,79 & 5,08 & 4,25 & 4,88 & 5,68 & 30,0 \\
\hline Área de olho de lombo $\left(\mathrm{cm}^{2}\right)$ & 108,2 & 110,2 & 94,6 & 106,9 & 126,0 & 15,2 \\
\hline Área de olho de lombo (cm²/100kg) & 43,5 & 44,5 & 44,3 & 44,4 & 43,3 & 12,8 \\
\hline
\end{tabular}

Médias seguidas de letras na mesma linha diferem $(p<0,05)$ pelo teste Tukey.

Archivos de zootecnia vol. 58, núm. 223, p. 378. 


\section{DESEMPENHO EM CONFINAMENTO COM OU SEM GORDURA PROTEGIDA}

alimentação restrita ou ad libitum encontraram valores de AOL de 61,16 e $48,55 \mathrm{~cm}^{2}$ e EG de 2,5 e 3,5 mm, respectivamente. Leme et al. (2000) observaram valores de AOL de $57,3 \mathrm{~cm}^{2}$ e EG de $2,7 \mathrm{~mm}$ para novilhos holandeses inteiros confinados e abatidos em pesos diferentes. Alves et al. (2004), ao avaliarem as características de carcaça de animais mestiços Holandês x Gir e Holandês x Guzerá em confinamento, obtiveram valores de espessura de gordura de 4,76 e 4,71 mm, e de AOL de 77,03 e 76,75 $\mathrm{cm}^{2}$, respectivamente.

Não houve interação $(p>0,05)$ entre a inclusão de gordura e os pesos de abate para nenhuma das variáveis estudadas.

A adição de gordura na dieta e os pesos de abate não afetaram $(p>0,05)$ os teores de umidade da carne, com valor médio de $73,95 \%$.

As quantidades de cinzas (tabela VI) no músculo Longissimus foram afetadas positivamente pela inclusão da gordura na dieta $(\mathrm{p}<0,05)$, com valores de $1,04 \%$ para $\mathrm{RSG}$ e $1,08 \%$ para RCG. Por outro lado, o aumento do peso de abate não influenciou o teor de cinzas, com valor médio de $1,06 \%$.

A diferença encontrada nos teores de cinzas $(p<0,05)$ não pode ser explicada como efeito dos tratamentos, pois não foi encontrada diferença entre as outras variáveis. O $\mathrm{CV}$ da matéria graxa $(26 \%)$ pode indicar que talvez alguma diferença poderia ter sido expressada, ficando no erro experimental.
Esta diferença no teor de cinzas foi pequena ou seja, $0,04 \%$ do total da composição do músculo, não proporcionando maiores alterações nesta composição.

Conteúdos de PB (tabela VI) não diferiram $(\mathrm{p}>0,05)$ quando da inclusão de gordura ou do aumento do peso de abate, sendo o valor médio de $22,76 \%$.

Valores médios de 2,50\% para MG (tabela VI) foram encontrados, sendo que a inclusão de gordura e o aumento do peso de abate não afetaram ( $\mathrm{p}>0,05)$ esta variável.

Valores de umidade (tabela VI) semelhantes foram descritos por Silva (2001) que, avaliando novilhas mestiças Nelore $\mathrm{x}$ Simental submetidas a diferentes fontes energéticas, encontraram músculos Longissimus com $74,5 \%$ de umidade.

O conteúdo de colesterol (tabela VI) no músculo Longissimus não variou ( $\mathrm{p}>0,05)$, quando da inclusão de gordura nas dietas e entre os pesos de abate, verificando-se 57,58 $\mathrm{mg} / 100 \mathrm{~g}$ de tecido em seu estado natural.

Ao avaliar a qualidade da carne e conteúdo de colesterol no músculo Longissimus dorsi de 24 novilhos Red Angus com oito meses de idade, terminados em confinamento em quatro pesos de abate $(340,373,400$ e $433 \mathrm{~kg})$, Costa et al. (2002) relataram valor médio de $2,35 \%$ para $\mathrm{MG}$, sendo que esta não foi influenciada pelos pesos de abate. Da mesma forma, o conteúdo

Tabela VI. Percentagem de umidade, cinzas, proteína bruta, matéria graxa total e concentração de colesterol da carne de novilhos alimentados com (RCG) ou sem (RSG) gordura em três pesos de abate. (Percentage of moisture, ash, crude protein, fat, and cholesterol concentration on meat of steers fed with (RCG) or without fat (RSG) slaughtered at three different weights).

\begin{tabular}{lcccccc}
\hline & \multicolumn{2}{c}{ Tratamentos } & \multicolumn{2}{c}{ Peso de abate (kg) } \\
& RSG & RCG & 450 & 510 & 600 & CV (\%) \\
& & & & & & \\
& 74,12 & 73,77 & 73,91 & 74,15 & 73,78 & 1,6 \\
Umidade (\%) & $1,04^{\mathrm{b}}$ & $1,08^{\mathrm{a}}$ & 1,08 & 1,07 & 1,03 & 5,2 \\
Cinzas (\%) & 22,82 & 22,69 & 22,17 & 22,82 & 23,28 & 5,8 \\
Proteína bruta (\%) & 2,50 & 2,49 & 2,34 & 2,16 & 2,98 & 26,0 \\
Matéria graxa total (\%) & 58,20 & 56,95 & 61,31 & 57,91 & 53,51 & 11,4 \\
Colesterol (mg/100g músculo) & & & &
\end{tabular}

Médias seguidas de letras na mesma linha diferem $(p>0,05)$ pelo teste Tukey. 
de colesterol não variou com o aumento do peso de abate, verificando-se 43,07 mg/100 g de músculo.

Arboitte et al. (2004), avaliando novilhos $5 / 8$ Nelore $-3 / 8$ Charolês, com idade média de 660 dias, em confinamento até atingirem os pesos de abate de 425,467 e $510 \mathrm{~kg}$ com uma dieta composta por $60 \%$ de volumoso e $40 \%$ de concentrado, obtiveram valor médio de $\mathrm{MG}$ de $1,63 \%$, sendo que os pesos de abate não influenciaram nesta variável, mas relataram uma tendência a aumentar, passando de 0,96 para $1,75 \%$, do menor para o maior peso de abate. Quanto ao colesterol, relataram valor médio de $53,12 \mathrm{mg} / 100 \mathrm{~g} \mathrm{de}$ músculo, não sendo influenciado pelos pesos de abate, apenas apresentando uma tendência de incremento linear.

\section{CONCLUSÕES}

O uso de gordura protegida (caroço de

\section{BIBLIOGRAFIA}

Abrahão, J.J.S. 2004. Resíduos da extração da fécula de mandioca em substituição ao milho: desempenho animal, digestibilidade, características da carcaça e da carne de tourinhos e novilhas terminados em confinamento. Tese (Doutorado em Zootecnia). Universidade Estadual de Maringá. 128 p.

Al-Hasani, S.M., J. Hlavac and M.W. Carpenter. 1993. Rapad determination of colesterol in single and multi-component prepared foods. J. AOAC Int., 76: 902-906.

Alves, D.D., M.F. Paulino, A.A. Backes, S.C. Valadares Filho e L.N. Rennó. 2004. Características de carcaça de bovinos Zebu e cruzados Holandês-Zebu $\left(F_{1}\right)$ nas fases de recria e terminação. Rev. Bras. Zootecn., 33: 12741284.

AOAC. 1984. American Official Analytical Chemist. Official methods of analysis, 14 ed. Washington, D.C. 1065 p.

Apple, J.K., M.E. Dikeman and D.D. Simm. 1991. Effects of synthetic hormone implants, singularly or in combinations, on performance, carcass traits, and Longissimus muscle palatability of algodão) proporcionou menor consumo de matéria seca para novilhos holandeses confinados, mas não exerceu influência no ganho de peso diário nem na conversão alimentar. Da mesma forma, não influenciou as características de carcaça destes animais.

Os pesos de abate não influenciaram o consumo, o desempenho e as características de carcaça de novilhos holandeses.

A inclusão de gordura na dieta e os pesos de abate não influenciaram os teores de proteína, matéria graxa, umidade e colesterol da carne de novilhos holandeses terminados em confinamento.

\section{AGRADECIMENTOS}

Conselho Nacional de Desenvolvimento Científico e Tecnológico-CNPq pela concessão das bolsas de pós-doutorado e produtividade em pesquisa.

Holstein steers. J. Anim. Sci., 69: 4437-4448. Arboitte, M.Z., J. Restle, D.C. Alves Filho, I.L. Brondani, P.S. Pacheco, L.F.G. Menezes e J. Perottoni. 2004. Composição física da carcaça, qualidade da carne e conteúdo de colesterol no músculo Longissimus dorsi de novilhos 5/8 Nelore - 3/8 Charolês terminados em confinamento e abatidos em diferentes estádios de maturidade. Rev. Bras. Zootecn., 33: 959-968.

Brondani, I.L., A.A.M. Sampaio, J. Restle, R.A.L.C. Bernardes, P.S. Pacheco, A.K. Freitas, F. Kuss e L.A.O. Peixoto. 2004. Aspectos quantitativos de carcaças de bovinos de diferentes raças, alimentados com diferentes níveis de energia. Rev. Bras. Zootecn., 33: 978-988.

Campos, O.F., R.S. Lizieire e P.A.P.M. Alves. 1996. Experimento do CNPGL/EMBRAPA com abate de machinhos da raça Holandesa aos seis meses de idade apresenta bons resultados. Gado Holandês, 36. 45 p.

Comerford, J.W., R.B. House, H.W. Harpster and J.B. Cooper. 1992. Effects of forage and protein source on feedlot performance and carcass traits of Holstein and crossbred beef steers. J. 


\section{DESEMPENHO EM CONFINAMENTO COM OU SEM GORDURA PROTEGIDA}

Anim. Sci., 70: 1022-1031.

Comerford, J.W., H.W. Harpster and V.H. Baumer 2001. The effects of grazing, liquid supplements, and implants on feedlot performance and carcass traits of Holstein steers. J. Anim. Sci., 79: 325-332.

Costa, E.C., J. Restle, L.L. Pascoal, F.N. Vaz, D.C. Alves Filho e M.Z. Arboitte. 2002. Desempenho de novilhos Red Angus superprecoces, confinados e abatidos com diferentes pesos. Rev. Bras. Zootecn., 31: 129-138.

Di Marco, O.N. 1994. Crescimiento y repuesta animal. Buenos Aires: Asociación Argentina de Producción Animal. 129 p.

Fernandes, H.J., M.F. Paulino, R.G.R. Martins, S.C. Valadares Filho, R.A. Torres, L.M. Paiva e A.T.S. Silva. 2004. Composição corporal de garrotes inteiros de três grupos genéticos nas fases de recria e terminação. Rev. Bras. Zootecn., 33: 1581-1590.

Galvão, J.G., C.A.A. Fontes, C.C. Pires, L.H.D.M. Carneiro, A.C. Queiroz e M.F. Paulino. 1991. Características e composição física da carcaça de bovinos não-castrados, abatidos em três estágios de maturidade (Estudo II) de três grupos raciais. Rev. Soc. Bras. Zootecn., 20: 502-512.

Hall, M.B. and A. Akinyode. 2000. Cottonseed hulls: working with a novel fiber source. In: Annual Florida Ruminant Nutrition Symposium. 11, 2000 Gainesville. Preceedings... Gainsville. p. $179-186$

Hill, G.M. and J.W. West. 1991. Rumen protected fat in Kline barley or corn diets for beef cattle: Digestibility, physiological and feedlot responses. J. Anim. Sci., 69: 3376-3388.

Hussein, H.S. and L.L. Berger. 1995. Feedlot performance and carcass characteristics of Holstein steers as affected by source of dietary protein and level of ruminally protected lysine and metionine. J. Anim. Sci., 63: 3503-3509.

INPE. 2002. Instituto Nacional de Pesquisas Espaciais. Sistema de Processamento de Informações Georreferenciadas SPRING 3.6.03 Tutoriais. São José dos Campos, SP.

Kearl, L.C. 1982. Nutrients requeriments of ruminants in developing countrys. International Feedstuffs Institute. Utah Agricultural Experimente Station. Utah State University. Logan. $271 \mathrm{p}$.

Leme, P.R., C. Boin, R.C.C. Margarido, L.O.
Tedeschi, J.C. O'farril, V. Hausknecht, G.L. Alleoni e A. Luchiari Filho. 2000. Desempenho em confinamento e características de carcaça de bovinos machos de diferentes cruzamentos abatidos em três faixas de peso. Rev. Bras. Zootecn., 29: 2347-2353. (Suplemento 2).

Levy, D., Z. Holzer and Y. Folman. 1975. Effect of concentrate:roughage ratio on the production of beef from Israeli-Frisian bulls slaughtered at different live weights. Anim. Prod., 20: 199205.

Magalhães, K.A., S.C. Valadares Filho e M.L. Chizzoti. 2003. Consumo e desempenho de novilhos de origem leiteira confinados alimentados com diferentes níveis de casca de algodão Em: Reunião Anual da Sociedade Brasileira de Zootecnia, 40., 2003a, Santa Maria. Anais... São Paulo: Sociedade Brasileira de Zootecnia/ Gnosis, [2003]. CD-ROM. Nutrição de Ruminantes.

Moletta, J.L. 1999. Utilização de soja grão ou caroço de algodão, na terminação de bovinos de corte em confinamento. Em: Reunião Anual da Sociedade Brasileira de Zootecnia, 36 p. 1999. Porto Alegre. Anais... São Paulo: Sociedade Brasileira de Zootecnia/Gnosis, [1999]. CD-ROM. Nutrição de Ruminantes.

Moody, W.G., J.R. Little and F.A. 1970. Thrift. Influence of lenghth of a high roughage ration on quantitative and qualitative characteristics of beef. J. Anim. Sci., 31: 866-873.

Müller, L. 1987. Normas para avaliação de carcaças e concurso de carcaças de novilhos. $2^{\mathrm{a}}$ ed. Santa Maria. Imprensa Universitária. UFSM. 1987. $31 \mathrm{p}$.

Ngidi, M.E., S.C. Loerch, F.L. Fluharty and D.L. Palmquist. 1990. Effects of calcium soaps of long-chain fatty acids on feedlot performance, carcass characteristics and ruminal metabolism of steers. J. Anim. Sci., 68: 2555.

NRC. 1996. National Research Council. Nutrient requeriments of beef cattle. Washington, D.C.

Patterson, D.C., C.A. Moore and R.W.J. Steen. 1994. The effects of plane of nutrition and slaughter weight on the performance and carcass composition of continental beef bulls given high forage diets. Anim. Prod., 58: 41-47.

Pereira, J.R.A. e P. Rossi. 1995. Manual prático de avaliação nutricional de alimentos. Piracicaba: FEALQ. 25 p.

Peron, A.J., C.A.A. Fontes e R.P. Lana. 2003.

Archivos de zootecnia vol. 58, núm. 223, p. 381. 
JORGE, ZEOULA, PRADO, SILVA, ANDRADE, PRADO, BUBLITZE MARQUES

Rendimento de carcaça e de seus cortes básicos e área corporal de bovinos de cinco grupos genéticos, submetidos a alimentação restrita $\mathrm{e}$ ad libitum. Rev. Bras. Zootecn., 22: 238-247.

Poore, M.H., T.P. Eck, R.S. Swingle and C.B. Theurer. 1989 Total starch and relative starch avaliability of grains. In: Bienal Conference On Rumen Function, 20: 35. Chicago. Abstracts... Chicago.

Prado, I.N., A.F. Branco, L.M. Zeoula, A.A. Pinto, G.V. Moraes e H.L.M. Moreira. 1995. Desempenho e características de carcaça de bovinos Nelore confinados, recebendo 15 ou $30 \%$ de caroço integral de algodão, bagaço autohidrolisado de cana-de-açúcar ou capim elefante. Arq. Biol. Tecnol., 38: 353-365.

Restle, J., L.A.S. Keplin e F.N. Vaz. 1997. Desempenho em confinamento de novilhos Charolês abatidos com diferentes pesos. Pesqui. Agropecu. Bras., 32: 857-860.

Ribeiro, T.R. 1997. Desempenho e qualidade de carcaça de bezerros holandeses alimentados com dietas contendo diferentes níveis de concentrado. Dissertação (Mestrado em Zootecnia). Universidade Federal de Viçosa. $89 \mathrm{p}$.

Rodrigues Filho, M., A.B. Mancio, R.P. Lana, P.R. Cecon, F.F. Silva, N.E.B. Rodriguese C.M. Veloso 2003. Desempenho e características de carcaça de novilhos de origem leiteira, alimentados com diferentes niveis de concentrado e de cama de frango. Rev. Bras. Zootecn., 32: 672-682.

Sartori, R. e M.R. Mollo. 2007. Influência da ingestão alimentar na fisiologia reprodutiva da fêmea bovina. Rev. Bras. Reprod. Anim., 31: 197-204.
Silva, D.J. 1990. Análise de alimentos: métodos químicos e biológicos. UFV. Viçosa. $165 \mathrm{p}$.

Silva, R.C. 2001. Composição muscular e perfil de ácidos graxos do músculo Longissimus dorsi de novilhos confinamento com substituição gradual do milho pela poupa de citrus peletizada. Disseratação (Mestrado em Química). Universidade Estadual de Maringá. 86 p.

Sniffen, C.J., J.D. O'connor, P.J. Van Soest, D.G. Fox and J.B. Russell. 1992. A net carbohydrate and protein system for evaluating cattle diets II. Carbohydrate and protein availability. J. Anim. Sci., 70: 3562-3577.

Sutter, F., M.M. Casutt, D.A. Ossowski, M.R.L Scheeder and M. Kreuzer. 2000. Comparative evaluation of rumen-protected fat, coconut oil and various oilseeds supplemented to fattening bulls. 1. Effects on growth, carcass and meat quality. Arch. Anim. Nutr., 53: 1-23.

Taxler, M.J., D.G. Fox, T.C. Perry, R.L. Dickerson and D.L. Williams. 1995. Influence of roughage and grain processing in high-concentrate diets on performance of long-fed Holstein steers. J. Anim. Sci., 73: 1888-1900.

Van Koevering, M.T., D.R. Gill, F.N. Owens, H.G. Dolezal and C.A. Strasia. 1995. Effects of time on feed on performance on feedlot steers, carcass characteristics, and tenderness and composition of Longissimus muscles. J. Anim. Sci., 73: 21-28.

Zinn, R.A., S.K. Gulati, A. Plascencia and J. Salinas. 2000. Influence of ruminal biohydrogenation on the feeding value of fat in finishing diets for feedlot cattle. J. Anim. Sci., 78: 1738-1746.

Archivos de zootecnia vol. 58, núm. 223, p. 382. 